\title{
New technique for conceptual selection of manufacturing process and material, case study: metal matrix composite component
}

\begin{abstract}
This article introduces a new technique involving concurrent engineering (CE) strategy and analytical network process (ANP) technique to form a ranking methodology as a part of the conceptual design selection (CS). The proposed method is referred as concurrent network $(\mathrm{CN})$. The objective of this study is to simultaneously consider of all features of product elements by implementing CE strategy. Furthermore, CN enables interdependence and interrelationship analysis between product elements by application of ANP. In this study, CN is utilized for a conceptual design of metal matrix composite (MMC) component. The results show that by using $\mathrm{CN}$, all important product parameters can be considered simultaneously during the CDS and the importance weights of manufacturing process parameters and material parameters which are related to MMC component performance are attained.
\end{abstract}

Keyword: Analytical network process; Conceptual design selection; Concurrent engineering; Manufacturing process selection; Material selection; Metal matrix composite component 